\title{
Haemolysis after mitral valve replacement with the Björk-Shiley and the Lillehei-Kaster disc valve prosthesis
}

\author{
S. Nitter-Hauge \\ From Laboratory of Cardiology, Medical Department B, University Hospital, Rikshospitalet, Oslo, Norway
}

The present study reports on the incidence and degree of intravascular haemolysis in 33 patients with BjörkShiley tilting disc prosthesis and in 34 patients with Lillehei-Kaster pivoting disc valve prosthesis in the mitral position examined 12 to 24 months after the operation. Serum haptoglobin, serum lactate dehydrogenase, serum bilirubin, and haemoglobin estimations were performed. Significant haemolysis was detected in 85 per cent of the patients. Haptoglobin was absent or reduced in 72 per cent, while raised values for serum lactate dehydrogenase were found in 43 per cent. The increase in lactate dehydrogenase was moderate and showed no correlation with blood flow through the prosthesis or with the gradient across the prosthesis. Most patients had normal haemoglobin and normal serum bilirubin values.

Although intravascular haemolysis was of little clinical significance, the increase in lactate dehydrogenase was significantly higher in patients with the Lillehei-Kaster prosthesis than in patients with the Björk Shiley prosthesis, indicating a slightly shorter red cell lifespan in the former group. The possible reasons for the difference between the two groups are discussed.

Intravascular haemolysis after heart valve replacement has been reviewed by several investigators since the initial report by Rose et al. (1954). Though the problems of haemolysis are better known in patients with an aortic valve prosthesis the occurrence of mild haemolysis is not unusual after mitral valve replacement with a Starr-Edwards prosthesis (Walsh, Starr, and Ritzman, 1969), a Smeloff-Cutter prosthesis (Milam et al., 1969), or a Kay-Shiley prosthesis (Vogel et al., 1969). The purpose of the present study was to assess the incidence and severity of chronic haemolysis in patients with one or other of the two new disc valve prostheses, the Björk-Shiley tilting disc valve and the Lillehei-Kaster pivoting disc valve.

\section{Subjects and methods}

The present report is based on studies of 67 unselected patients with isolated mitral valve replacement. There were 27 men and 40 women, varying in age between 33 and 65 years, with a mean age of 56.8 years. In 33 patients, the prosthesis inserted

Received 1 October 1975. was a Björk-Shiley tilting disc valve ${ }^{1}$ (Björk, 1972), while in 34 patients a Lillehei-Kaster pivoting disc valve was used (Lillehei et al., 1970). The valve sizes used are presented in the Table.

The re-examination took place 12 to 24 months after the operation. During the observation period all patients were on maintenance treatment with 'Pyrolite carbon disc.

T A B L E Sizes of prosthetic valves used

Björk-Shiley prosthesis

\begin{tabular}{llc}
\hline Valve size & Orifice area $\left(\mathrm{cm}^{2}\right)$ & No. of patients \\
\hline 25 & $3 \cdot 2$ & 3 \\
27 & $3 \cdot 8$ & 2 \\
$29-31$ & $4 \cdot 6$ & 28
\end{tabular}

Lillehei-Kaster prosthesis

\begin{tabular}{llc}
\hline Valve size & Orifice area $\left(\mathrm{cm}^{2}\right)$ & No. of patients \\
\hline 18 & $2 \cdot 5$ & 4 \\
20 & $3 \cdot 1$ & 8 \\
22 & 3.8 & 11 \\
$25-28$ & 4.9 & 11
\end{tabular}



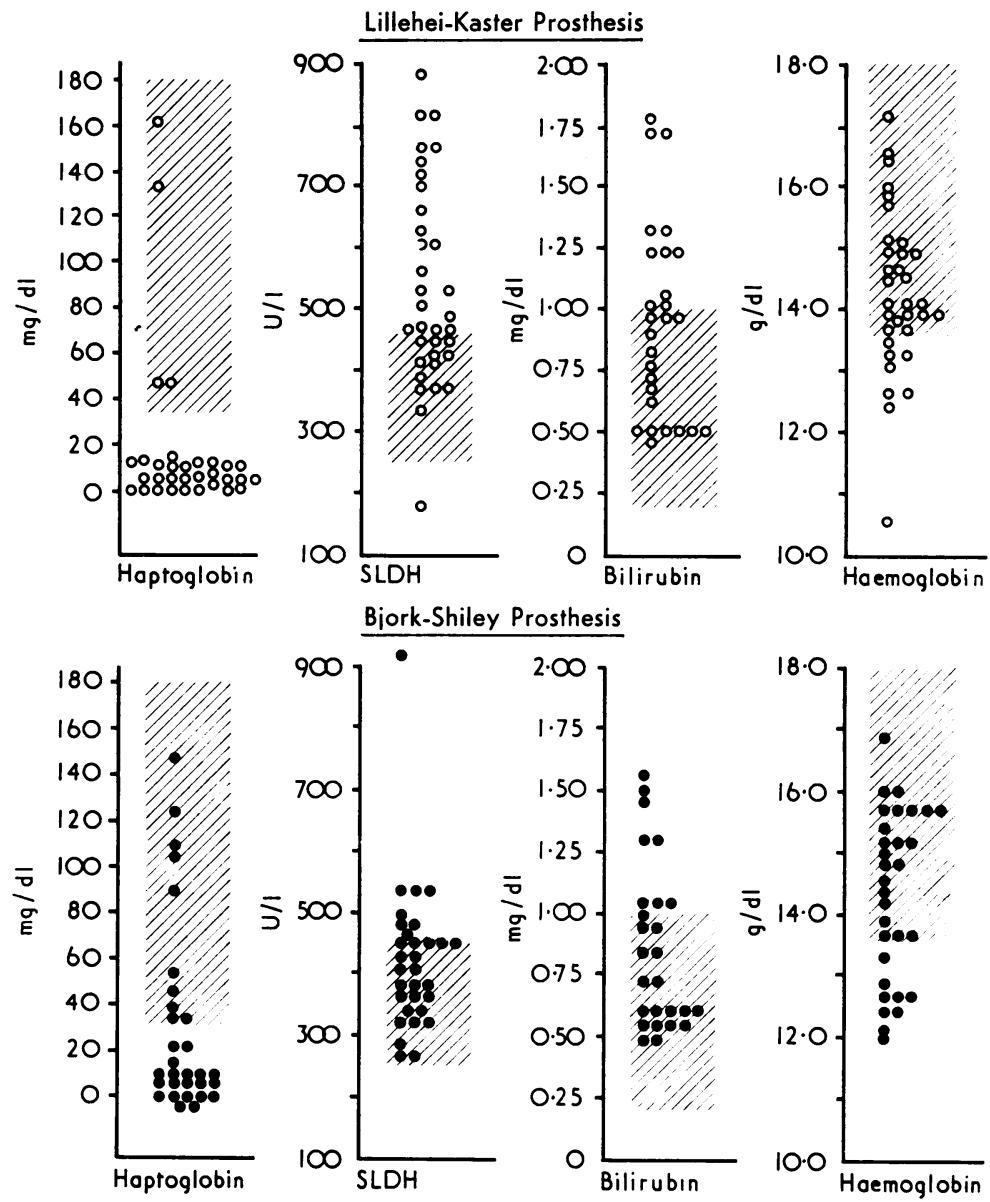

FIG. 1 Serum haptoglobin, serum lactate dehydrogenase (SLDH), serum bilirubin, and haemoglobin concentration in patients with Lillehei-Kaster (above) or Björk-Shiley (below) prosthetic valve. The shaded area marks normal range.

digitoxin, diuretics, and anticoagulant agents. None of these patients received iron supplements.

To assess possible haemolysis, the following laboratory tests were performed: haemoglobin concentration by cyanmethaemoglobin method (normal range 13.5 to $18.0 \mathrm{~g} / \mathrm{dl}$ ), serum bilirubin by Jaffe's reaction (normal range 0.2 to $1.0 \mathrm{mg} / \mathrm{dl}$ ), haptoglobin by saturation with haemoglobin and measuring of the peroxidase activity (normal range 30 to $180 \mathrm{mg} / \mathrm{dl}$ ), and lactate dehydrogenase (SLDH) activity in serum using Kabi's reagents (normal range 150 to $450 \mathrm{u} / 1$ ).

In addition to investigation for evidence of haemolysis in all patients, postoperative haemodynamic data were available in most patients: these included resting cardiac output (Fick's principle) and mean diastolic pressure gradient across the mitral valve determined by planimetric integration of simultaneously recorded pulmonary artery wedge pressure and left ventricular pressure after correction for delay. Left ventricular cineangiography showed a normally functioning prosthetic valve. There was no evidence for gastrointestinal bleeding, infection, or drug allergy in any patient.

Arithmetical means, standard deviations, and coefficients of correlations were calculated as described by Snedecor (1956). Regression lines were drawn according to equations found by the method of least squares. Statistical significance of differences between means was made using Student's t-test. P values higher than 0.05 were not considered to be significant. 


\section{Results}

Of the 67 patients studied, $57(85 \%)$ showed one or several unequivocal signs of intravascular haemolysis. Fig. 1 shows the individual data for haptoglobin, lactate dehydrogenase, and bilirubin in serum, and haemoglobin, in patients with a BjörkShiley or Lillehei-Kaster prosthesis.

Haptoglobin was absent or greatly reduced in $48(72 \%)$ of the patients studied. The mean value for haptoglobin was $31.0 \mathrm{mg} / \mathrm{dl}$ in patients with a Björk-Shiley prosthesis and $15.8 \mathrm{mg} / \mathrm{dl}$ in patients with a Lillehei-Kaster prosthesis. The number of patients without haptoglobin was approximately the same in both groups. SLDH values were raised in $29(43 \%)$ of the patients studied. The mean value for SLDH was $425.5 \pm$ $124.8 \mathrm{U} / 1$ in patients with a Björk-Shiley prosthesis and $533.5 \pm 162.6 \mathrm{U} / 1$ in patients with a Lillehei-Kaster prosthesis, showing significant higher values in the latter group $(t=2.973, P<0.01)$. Seventeen patients $(25 \%)$ had a raised serum bilirubin level. Of these 17 patients, 16 had additional signs of haemolysis, while one patient (bilirubin $1.8 \mathrm{mg} / \mathrm{dl}$ ) showed no other indication of haemolysis. The mean value was $0.87 \pm 0.32 \mathrm{mg} / \mathrm{dl}$ in patients with Björk-Shiley prosthesis and $0.92 \pm 0.39 \mathrm{mg} / \mathrm{dl}$ in patients with Lillehei-Kaster prosthesis. The intergroup difference was not significant $(t=0.490, P>0.05)$. Seventeen $(25 \%)$ of the patients examined had abnormal low values for haemoglobin. Of these 17 patients, 13 had additional signs of haemolysis, while 4 showed no other indications of haemolysis. The mean value

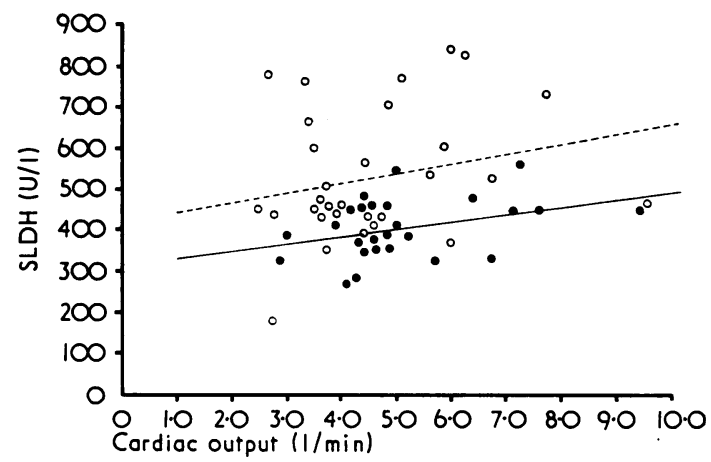

FIG. 2 Plot diagram with regression lines showing the relation between SLDH and cardiac output in patients with prosthetic valve. Open circles-LilleheiKaster prosthesis: regression line $y=36 \cdot 8 \times+366 \cdot 1$, $r=0.368, P>0.05$ (interrupted line). Closed circlesBjörk-Shiley prosthesis: regression line $y=18 \cdot 2$ $x+308 \cdot 1, r=0.383, P>0.05$ (solid line).

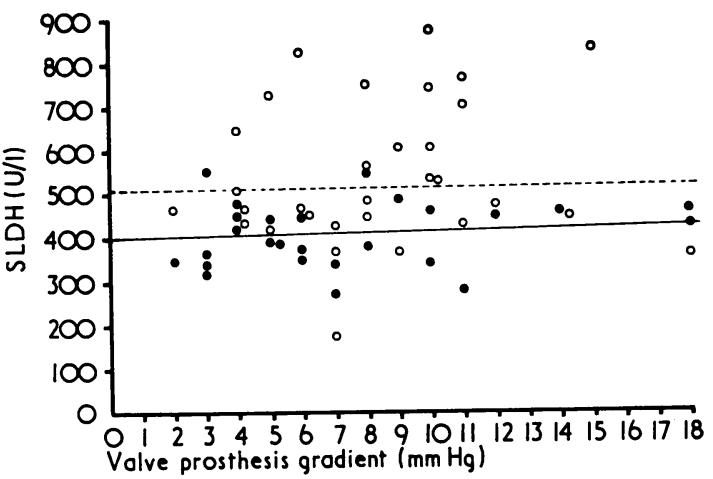

FIG. 3 Plot diagram with regression lines showing the relation between SLDH and gradient across prosthetic valve. Open circles-Lillehei-Kaster prosthesis: regression line $y=2 \cdot 4 \times+513 \cdot 0, r=0.051$, $P>0.05$ (interrupted line). Closed circles-BjörkShiley prosthesis: regression line $y=2 \cdot 0 \times+386 \cdot 9$, $r=0 \cdot 124, P>0.05$ (solid line).

for patients with a Björk-Shiley prosthesis was $14 \cdot 32 \pm 1 \cdot 34 \mathrm{~g} / \mathrm{dl}$, and for patients with a LilleheiKaster prosthesis $14.27 \pm 1.31 \mathrm{~g} / \mathrm{dl}$. The intergroup difference was not statistically significant $(\mathrm{t}=0.138, \mathrm{P}>0.05)$.

Fig. 2 shows that there is no correlation between flow through the prosthesis (cardiac output) and the severity of haemolysis as assessed by the SLDH levels. As seen in Fig. 3, SLDH values in both groups of patients varied independently of the diastolic gradient across the valve.

\section{Discussion}

Chronic haemolytic anaemia is an unwanted effect of prosthetic replacement of cardiac valves. In this type of haemolysis the SLDH is increased because of enzyme liberation from damaged erythrocytes, and the degree of rise in SLDH levels correlates with the degree of shortening of the ${ }^{51} \mathrm{Cr}$ red cell survival time (Walsh et al., 1969; Myhre, Rasmussen, and Andersen, 1970). Free plasma haemoglobin liberated from ruptured erythrocytes binds to haptoglobin or is excreted by the kidney when the plasma haemoglobin level exceeds the binding capacity of haptoglobin. Serum haptoglobin is usually absent or much reduced in the presence of moderate continuous haemolysis (Eyster, Mayer, and McKenzie, 1968; Myhre, Dale, and Rasmussen, 1971). Hyperbilirubinaemia is a more uncommon finding, since only slight to moderate extravascular haemolysis is seen in patients with a prosthetic valve (Wallace et al., 
1970a; Wallace, Kenepp, and Blakemore, 1970b). Anaemia is present in only a small percentage of cases.

In the present study, clinically manifest haemolysis in the form of haemolytic anaemia was not seen in any patient. Mild haemolysis, however, was present in the majority, as shown by slightly increased SLDH and decreased haptoglobin concentrations

Interestingly, we were able to show differences between the two types of prosthetic valves used. Patients with a Lillehei-Kaster prosthesis were apparently more predisposed to haemolysis than patients with a Björk-Shiley prosthesis. Perhaps the most widely accepted theory is that destruction of erythrocytes after replacement with a valve prosthesis is the result of an increase in shearing stress from turbulence and from increased diastolic or systolic gradient (Nevaril et al., 1968). The two types of disc valve used in the present study are both characterized by a central flow pattern with little turbulence. Furthermore, the mitral valve is situated in a relatively low pressure system and is less likely to produce the shearing stress required to damage red cells. In our study, increased concentrations of serum lactate dehydrogenase showed no significant correlation with either the peak diastolic gradient across the valve or the flow through the valve.

Most probably, the difference in severity and incidence of haemolysis between patients with a Björk-Shiley prosthesis and those with a LilleheiKaster prosthesis is related to differences in valve design. While the Lillehei-Kaster pivoting disc valve closes completely during ventricular systole, there is slight regurgitation at the periphery of the Björk-Shiley disc valve after closure; this has been calculated to be about 5 per cent of the forward stroke volume (Björk, 1975). It is possible that the mechanical trauma to the red blood cell is less in this non-overlapping valve compared with an overlapping valve prosthesis, and that crushing of the erythrocytes between the disc and the valve seat may explain the more severe haemolysis seen in patients with the Lillehei-Kaster valve.

There is no significant difference between the results of the present study and those of a previous investigation of haemolysis after insertion of a Björk-Shiley or Lillehei-Kaster prosthesis in the aortic position (Nitter-Hauge et al., 1974). Apparently, the position of the prosthesis is of only minor importance in this connexion. Similarly, no difference has been observed between mitral and aortic Starr-Edwards valves (Crexells et al., 1972), though these valves in general were more traumatic to red cells than the disc valves used by us.

\section{References}

Björk, V. O. (1972). The pyrolite carbon occluder for the Björk-Shiley tilting disc valve prosthesis. Scandinavian fournal of Thoracic and Cardiovascular Surgery, 6, 109.

Björk, V. O. (1975). The hemodynamic characteristics of the Björk-Shiley mitral valve prosthesis. In International Symposium on the Mitral Valve, Paris. Fondation A. De Rothschild.

Crexells, C., Aerichide, N., Bonny, Y., Lepage, G., and Campeau, L. (1972). Factors influencing hemolysis in valve prosthesis. American Heart fournal, 84, 161.

Eyster, E., Mayer, K., and McKenzie, S. (1968). Traumatic hemolysis with iron deficiency anemia in patients with aortic valve lesions. Annals of Internal Medicine, 68, 995.

Lillehei, C. W., Kaster, R. L., Starek, P. J., and Bloch, J. R. (1970). A new central flow pivoting disc aortic and mitral prosthesis. Initial clinical experience. American fournal of Cardiology, 26, 668.

Milam, J. D., Bloodwell, R. D., Hallmann, G. L., and Cooly, D. A. (1969). Evaluation of hemolysis in patients with cardiac valve prosthesis: A comparative study. In Prosthetic Heart, p. 663. Ed. by L. A. Brewer. Charles C. Thomas, Springfield, Illinois.

Myhre, E., Dale, J., and Rasmussen, K. (1971). Quantitative aspects of hemolysis in aortic valvular disease and ball valve prosthesis. Acta Medica Scandinavica, 189, 101.

Myhre, E., Rasmussen, K., and Andersen, A. (1970). Serum lactic dehydrogenase activity in patients with prosthetic heart valves: a parameter of intravascular hemolysis. American Heart fournal, 80, 463.

Nevaril, C. G., Lynch, E. C., Alfrey, C. P., and Hellums, J. D. (1968). Erythrocyte damage and destruction induced by shearing stress. Fournal of Laboratory and Clinical Medicine, 71, 784.

Nitter-Hauge, S., Sommerfelt, S. C., Hall, K-V., Fröysaker, T., and Efskind, L. (1974). Chronic intravascular haemolysis after aortic disc valve replacement. Comparative study between Lillehei-Kaster and Björk-Shiley disc valve prostheses. British Heart Fournal, 36, 781.

Rose, J. C., Hufnagel, C. A., Freis, E. D., Harvey, W. P., and Partenope, E. A. (1954). The hemodynamic alterations produced by a plastic valvular prosthesis for severe aortic insufficiency in man. Fournal of Clinical Investigation, 33, 891.

Snedecor, G. W. (1956). Statistical Methods Applied to Experiments in Agriculture and Biology, 5th ed. Iowa State College Press, Ames, Iowa.

Vogel, J. H. K., Paton, B. C., Overy, H. R., and Blount, S. G. (1969). Abnormal hemodynamic function after disc mitral valve replacement. Circulation, 39, Suppl. I, 141.

Wallace, H. W., Coburn, R. F., Habboushe, F., Blakemore, W. S., and Shepard, C. E. (1970a). Mechanically induced intravascular and extravascular hemolysis in dogs. Circulation Research, 26, 347.

Wallace, H. W., Kenepp, D. L., and Blakemore, W. S. (1970b). Quantitation of red blood cell destruction associated with valvular disease and prosthetic valve. fournal of Thoracic and Cardiovascular Surgery, 60, 842.

Walsh, J. R., Starr, A., and Ritzmann, L. W. (1969). Intravascular hemolysis in patients with prosthetic valves and valvular heart disease. Circulation, 39, Suppl. I, 135.

Requests for reprints to Dr. Sigurd Nitter-Hauge, Laboratory of Cardiology, Medical Department B, Rikshospitalet, National Hospital of Norway, University Hospital, Oslo, Norway. 